\title{
SINTESIS DAN STUDI STABILITAS NANOPARTIKEL PERAK TERTUDUNG ASAM SALISILAT
}

\author{
Rizky Noviani Ridwan ${ }^{1}$, Gusrizal Gusrizal ${ }^{1 *}$, Nurlina Nurlina ${ }^{1}$, Sri Juari Santosa ${ }^{2}$ \\ ${ }^{1}$ Jurusan Kimia, Fakultas Matematika dan Ilmu Pengetahuan Alam, Universitas Tanjungpura \\ Jl. Prof. Dr. H. Hadari Nawawi, Pontianak, Indonesia \\ ${ }^{2}$ Departemen Kimia, Fakultas Matematika dan Ilmu Pengetahuan Alam, Universitas Gadjah \\ Mada
}

Sekip Utara, PO BOX BLS 21 Yogyakarta 55281, Indonesia

"Corresponding author:gusrizal@chemistry.untan.ac.id

\begin{tabular}{l}
\hline ARTICLE INFO \\
Article history: \\
Received 24 \\
September 2018 \\
Accepted 19 \\
November 2018 \\
Available online \\
30 December 2018 \\
Keywords: \\
Antioksidan,Citrus \\
microcarpa Bunge, \\
Limonin, Triterpenoid
\end{tabular}

1. Pendahuluan

Penelitian mengenai nanopartikel perak saat ini sedang mengalami perkembangan yang pesat, baik mengenai pemanfaatan maupun metode sintesis nanopartikel perak. Nanopartikel perak telah dimanfaatkan dalam berbagai bidang, antara lain sebagai antibakteri dan antiinflamasi $^{[1]}$ serta sensor ion logam ${ }^{[2]}$. Nanopartikel perak dapat disintesis menggunakan metode reduksi kimia yang dikenal dengan bottom-up approach. Pada metode ini diperlukan agen pereduksi dan agen penudung selain sumber ion perak. Agen pereduksi digunakan untuk mereduksi ion $\mathrm{Ag}^{+}$menjadi $\mathrm{Ag}^{0}$. Beberapa senyawa kimia yang telah digunakan sebagai agen pereduksi dalam sintesis nanopartikel perak antara lain natrium sitrat ${ }^{[2]}$, natrium borohidrida ${ }^{[3]}$, asam askorbat ${ }^{[4]}$, dan glukosa ${ }^{[5]}$. Permasalahan utama dalam sintesis nanopartikel perak yaitu aglomerasi yang menyebabkan ukuran nanopartikel perak menjadi lebih besar. Nanopartikel perak yang baru terbentuk dapat terus tumbuh dan mengalami aglomerasi. Aglomerasi dapat

Silver nanoparticles capped with salicylic acid have been synthesized by reduction of silver nitrate with salicylic acid without additional capping agent. In the formation of silver nanoparticles, the solution of silver nitrate was first mixed with the $\mathrm{pH} 11$ salicylic acid solutions at a mole ratio of 1:40. The mixture was heated for 45 minutes in a boiling water bath. The formation of silver nanoparticles was indicated by the appearance of yellow color and monitored using UVVis spectrophotometer. The maximum peak of resulted silver nanoparticles appeared in the range of $410-420 \mathrm{~nm}$ with the average size of particles was $66 \pm 28 \mathrm{~nm}$. Stability test over a period of 16 weeks showed that silver nanoparticles capped with salicylic acid were stable. The results of stability test show that salicylic acid simultaneously act as reducing as well as capping agent in the formation of silver nanoparticles.

(C) 2018 IJoPAC. All rights reserved 
dicegah dengan menambahkan agen penudung ${ }^{[2]}$. Polivinil alkohol ${ }^{[6]}$, gelatin ${ }^{[2]}$, dan kitosan ${ }^{[5]}$ adalah beberapa agen penudung yang telah digunakan dalam sintesis nanopartikel perak.

Agen pereduksi dan agen penudung dapat mempengaruhi ukuran dan stabilitas nanopartike ${ }^{[7]}$ sehingga banyak penelitian yang bertujuan untuk mencari agen pereduksi dan agen penudung baru. Beberapa kasus menunjukkan bahwa agen pereduksi dapat berperan ganda sekaligus sebagai agen penudung. Telah dilaporkan bahwa asam hidroksibenzoat dapat berperan ganda sebagai agen pereduksi sekaligus agen penudung dalam sintesis nanopartikel perak $^{[8][9]}$.

Asam hidroksibenzoat memiliki tiga jenis isomer, yaitu asam $o$-hidroksibenzoat atau asam salisilat, asam $m$-hidroksibenzoat, dan asam $p$-hidroksibenzoat. Ketiga isomer ini telah digunakan sebagai agen pereduksi dan agen penudung dalam sintesis nanopartikel perak ${ }^{[8][9]}$. Kemampuan ketiga isomer asam hidroksibenzoat sebagai agen pereduksi sekaligus agen penudung disebabkan oleh kehadiran gugus hidroksil $(-\mathrm{OH})$ dan gugus karboksil $(-\mathrm{COOH})$ pada struktur asam hidroksibenzoat. Gugus hidroksil berperan sebagai gugus pereduksi sedangkan gugus karboksil berperan sebagai penudung untuk menjaga stabilitas nanopartikel perak. Nanopartikel perak yang disintesis menggunakan asam $m$ - dan $p$-hidroksibenzoat memiliki kestabilan yang tinggi karena dapat bertahan sampai 40 minggu masa penyimpanan ${ }^{[10]}$.

Pada tulisan ini disajikan kajian mengenai sintesis dan stabilitas nanopartikel perak tertudung asam salisilat untuk melengkapi data studi stabilitas nanopartikel perak tertudung isomer asam hidroksibenzoat yang telah ada sebelumnya ${ }^{[10]}$. Hal ini penting dilakukan untuk mengetahui kemampuan asam salisilat sebagai agen penudung dalam melindungi ukuran nanopartikel perak disamping sebagai agen pereduksi. Stabilitas nanopartikel perak tertudung asam salisilat diamati melalui perubahan spektra resonansi plasmon permukaan (surface plasmon resonance) nanopartikel perak selama masa penyimpanan.

\section{Material dan Metode}

\subsection{Material}

Pada penelitian ini digunakan bahan kimia yang tersedia secara komersil tanpa penanganan lanjutan seperti perak nitrat (Merck), asam salisilat (Merck), dan natrium hidroksida (Merck). Untuk karakterisasi nanopartikel digunakan particle size analyzer (HORIBA SZ-100) dan spektrofotometer UV-Vis (Shimadzu UV-1280).

\subsection{Sintesis Nanopartikel Perak}

Sintesis nanopartikel perak dilakukan dengan mereaksikan $5 \mathrm{~mL}$ perak nitrat dengan $5 \mathrm{~mL}$ asam salisilat dalam sebuah tabung reaksi. Asam salisilat terlebih dahulu dikondisikan hingga memiliki pH 11 dengan penambahan larutan natrium hidroksida. Campuran kemudian perak nitrat dan asam salisilat kemudian dipanaskan di dalam penangas air mendidih sampai terjadi pembentukan nanopartikel perak yang ditunjukkan oleh perubahan warna larutan dari tidak berwarna menjadi kuning kecoklatan ${ }^{[8]}$. Nanopartikel yang terbentuk kemudian didinginkan dan selanjutnya diukur menggunakan spektrofotometer UV-Vis.

\subsection{Karakterisasi Nanopartikel Perak}

Pembentukan nanopartikel perak diamati melalui pengukuran spektra resonansi plasmon permukaan menggunakan spektrofotometer UV-Vis. Pengukuran nanopartikel perak dengan spektrofotometer UV-Vis menggunakan kuvet dengan ketebalan $1 \mathrm{~cm}$ dan diukur pada rentang panjang gelombang 300-800 $\mathrm{nm}$. Pengukuran ukuran dan distribusi partikel dilakukan 
menggunakan particle size analyzer. Larutan nanopartikel perak diambil sebanyak $3 \mathrm{~mL}$ dan diukur dengan sudut hamburan $90^{\circ}$.

\subsection{Pengukuran Stabilitas Nanopartikel Perak}

Nanopartikel perak hasil sintesis diukur stabilitasnya selama 16 minggu masa penyimpanan. Pengukuran stabilitas dilakukan dengan mengamati perubahan spektra resonansi plasmon permukaan nanopartikel yang diperoleh dari pengukuran dengan spektrofotometer UV-Vis. Parameter yang diamati yaitu posisi panjang gelombang maksimum, intensitas puncak serapan dan lebar puncak atau full width half maximum $(\mathrm{FWHM})^{[10]}$.

\section{Hasil dan Pembahasan}

\subsection{Penentuan Waktu Reaksi Optimum}

Variasi waktu reaksi dilakukan untuk mengetahui waktu reaksi optimum yang diperlukan asam salisilat dalam mereduksi perak sehingga dapat digunakan pada sintesis nanopartikel perak untuk tahap selanjutnya. Penentuan waktu reaksi optimum dilakukan dengan menggunakan variasi waktu reaksi 15, 30, 45, 60, 90, dan 120 menit. Proses sintesis nanopartikel perak dalam penentuan waktu reaksi optimum menggunakan larutan perak nitrat berkonsentrasi $2,5 \times 10^{-4} \mathrm{M}$ dan asam salisilat berkonsentrasi $1 \times 10^{-2} \mathrm{M}$. Sebelum direaksikan dengan perak nitrat, $\mathrm{pH}$ asam salisilat terlebih dahulu diatur menjadi 11 dengan penambahan natrium hidroksida. Volume perak nitrat dengan asam salisilat yang digunakan yaitu masingmasing $5 \mathrm{~mL}$. Campuran perak nitrat dengan asam salisilat kemudian dipanaskan di dalam penangas air mendidih dan nanopartikel perak yang dihasilkan diukur menggunakan spektrofotometer UV-Vis pada setiap variasi waktu dan menghasilkan spektra resonansi plasmon permukaan sebagaimana terlihat pada Gambar 1.

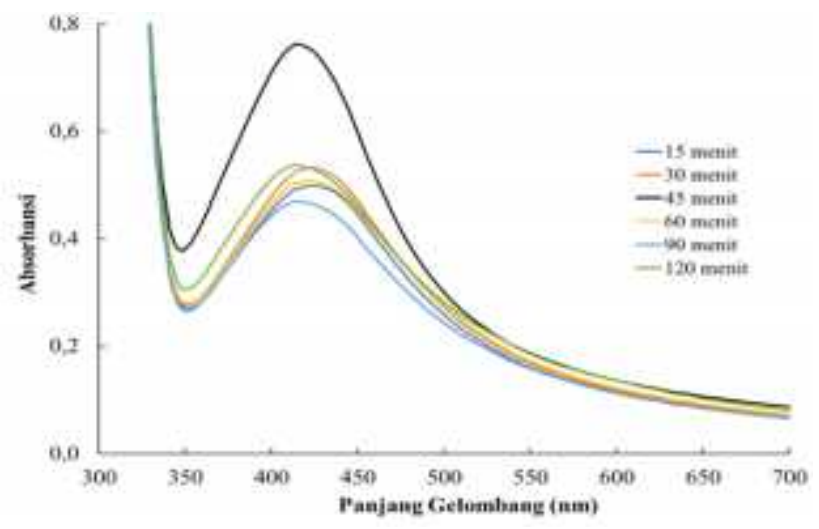

Gambar 1. Spektra resonansi plasmon permukaan nanopartikel perak yang disintesis pada berbagai waktu reaksi

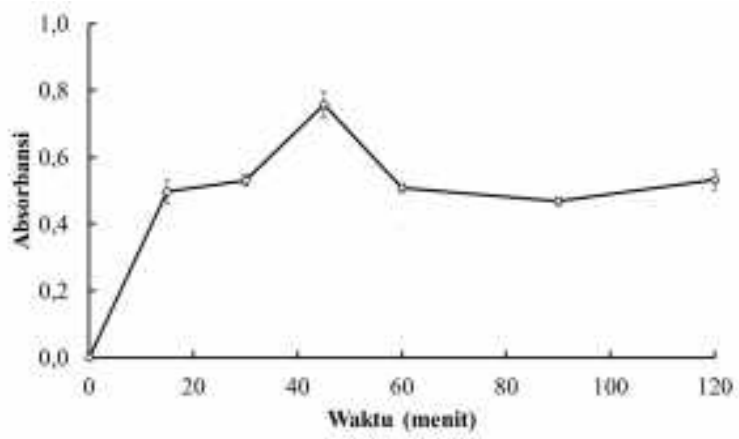

Gambar 2. Intensitas puncak serapan nanopartikel perak yang disintesis pada berbagai waktu reaksi 
Pembentukan nanopartikel perak terlihat dari perubahan warna larutan yang tidak berwarna menjadi kuning kecoklatan dan dapat diamati melalui adanya puncak serapan pada panjang gelombang 410-420 $\mathrm{nm}^{[9][11]}$. Gambar 1 menunjukkan bahwa nanopartikel perak tertudung asam salisilat terbentuk pada setiap variasi waktu reaksi dengan intensitas absorbansi yang berbeda-beda. Intensitas puncak serapan menunjukkan jumlah nanopartikel peak yang terbentuk. Gambar 2 menunjukkan bahwa terjadi peningkatan absorbansi sampai waktu reaksi selama 45 menit yang menunjukkan masih terjadinya reaksi reduksi perak oleh asam salisilat selama rentang waktu tersebut, namun terjadi penurunan absorbansi ketika reaksi berlangsung melebihi waktu 45 menit. Selain penurunan intensitas puncak serapan, terjadi pelebaran puncak serapan (FWHM) dari 132 menjadi $157 \mathrm{~nm}$ ketika waktu reaksi diperpanjang dari 45 menjadi 120 menit. Hal ini mengindikasikan bahwa terjadi peningkatan ukuran partikel. Seiring dengan bertambahnya waktu reaksi, nanopartikel perak yang terbentuk akan semakin banyak, namun pembentukan nanopartikel perak yang melebihi waktu reaksi optimum dapat menghasilkan ukuran partikel yang lebih besar ${ }^{[11]}$. Berdasar Gambar 2, waktu reaksi optimum yang dipilih dalam sintesis nanopartikel perak yaitu selama 45 menit karena pada waktu tersebut dihasilkan nanopartikel perak dengan jumlah paling banyak.

Berdasarkan penelitian yang telah dilakukan, terdapat perbedaan waktu reaksi dalam sintesis nanopartikel perak dari isomer asam salisilat yaitu asam $p$-hidroksibenzoat dan asam $m$-hidroksibenzoat. Asam $p$-hidroksibenzoat memiliki waktu reaksi optimum 1 jam dan asam $m$-hidroksibenzoat memiliki waktu reaksi optimum 15 menit ${ }^{[8][9]}$. Adanya perbedaan waktu reaksi ini disebabkan oleh perbedaan posisi gugus hidroksil pada struktur asam hidroksibenzoat.

\subsection{Penentuan Rasio Mol Perak Nitrat dengan Asam Salisilat}

Waktu reaksi optimum yang telah diperoleh digunakan sebagai waktu acuan untuk sintesis nanopartikel perak pada penentuan rasio mol perak nitrat dengan asam salisilat. Penentuan rasio mol perak nitrat dengan asam salisilat dilakukan untuk mengetahui perbandingan optimum agar asam salisilat dapat bekerja dengan lebih baik sebagai agen pereduksi dan agen penudung dalam sintesis nanopartikel perak. Agen pereduksi dapat mempengaruhi ukuran nanopartikel perak yang dihasilkan, dimana konsentrasi agen pereduksi yang sesuai dapat meningkatkan laju pembentukan nanopartikel perak. Di samping itu, agen penudung memiliki kemampuan untuk membatasi pertumbuhan nanopartikel perak sehingga menghasilkan nanopartikel perak yang homogen ${ }^{[5]}$. Penentuan rasio mol perak nitrat dengan asam salisilat dilakukan dengan memvariasikan konsentrasi asam salisilat yaitu dari $2,5 \times 10^{-3} \mathrm{M}$ sampai $2,5 \times 10^{-2} \mathrm{M}$ dan menggunakan larutan perak nitrat berkonsentrasi $2,5 \times 10^{-4} \mathrm{M}$. Pada sintesis nanopartikel perak digunakan volume larutan perak dan pereduksi masing-masing $5 \mathrm{~mL}$ dengan waktu reaksi selama 45 menit.

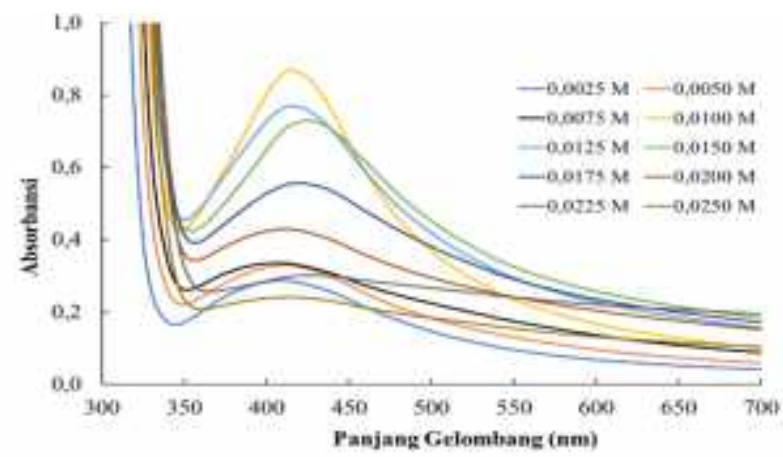

Gambar 3. Spektra resonansi plasmon permukaan nanopartikel perak yang disintesis dengan berbagai konsentrasi asam salisilat 
Gambar 3 menunjukkan spektra resonansi plasmon permukaan nanopartikel perak dari setiap variasi konsentrasi asam salisilat yang digunakan. Nanopartikel perak terbentuk pada setiap variasi konsentrasi asam salisilat yang digunakan karena terjadi perubahan warna larutan dari tidak berwarna menjadi kuning kecoklatan dan terdapat puncak serapan pada panjang gelombang 410-420 nm. Intensitas absorbansi mengalami peningkatan seiring dengan peningkatan konsentrasi asam salisilat dari konsentrasi terendah yaitu $2,5 \times 10^{-3} \mathrm{M}$ dengan nilai absorbansi 0,281 hingga absorbansi tertinggi pada konsentrasi $1,0 \times 10^{-2} \mathrm{M}$ dengan nilai absorbansi 0,862. Peningkatan intensitas absorbansi menunjukkan semakin banyak nanopartikel perak yang terbentuk ${ }^{[8]}$. Namun, terjadi penurunan intensitas absorbansi dan pelebaran puncak serapan bila menggunakan asam salisilat dengan konsentrasi $1,25 \times 10^{-2}$ sampai $2,5 \times 10^{-2} \mathrm{M}$. Bila digunakan asam salisilat dengan konsentrasi $1,0 \times 10^{-2} \mathrm{M}$ diperoleh FWHM dengan ukuran $137 \mathrm{~nm}$ dan $384 \mathrm{~nm}$ bila menggunakan asam salisilat dengan konsentrasi $2,5 \times 10^{-2} \mathrm{M}$. Hal tersebut mengindikasikan peningkatan konsentrasi asam salisilat dapat mempengaruhi jumlah, ukuran, dan heterogenitas dari nanopartikel yang dihasilkan ${ }^{[8][9]}$. Gambar 4 menunjukkan hubungan antara variasi konsentrasi asam salisilat dengan intensitas absorbansi nanopartikel perak. Hasil maksimum diperoleh pada sintesis nanopartikel perak dengan konsentrasi asam salisilat $1 \times 10^{-2} \mathrm{M}$, dimana rasio mol antara perak nitrat dengan asam salisilat adalah 1:40.

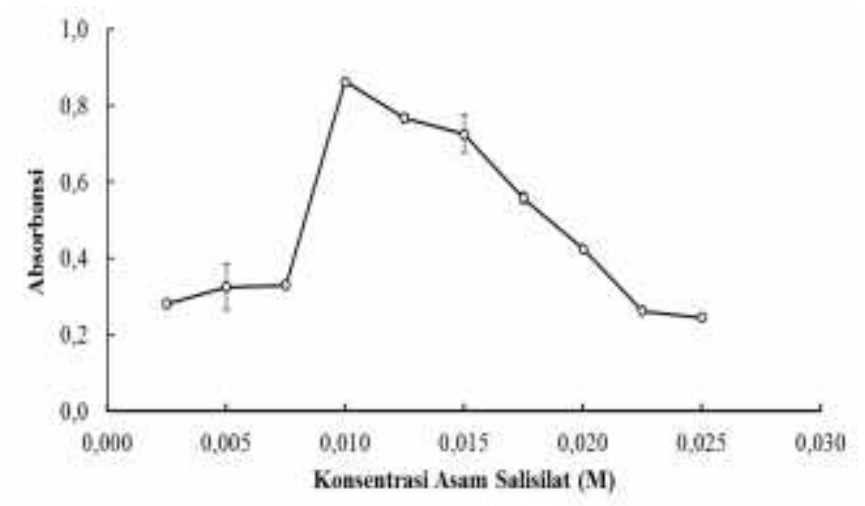

Gambar 4. Intensitas puncak serapan nanopartikel perak yang disintesis dengan berbagai konsentrasi asam salisilat

Berdasarkan hasil analisis menggunakan PSA (particle size analyzer) diperoleh ukuran ratarata nanopartikel perak tertudung asam salisilat sebesar $66 \pm 28 \mathrm{~nm}$. Jika dibandingkan dengan nanopartikel perak yang disintesis menggunakan asam $m$ - dan $p$-hidroksibenzoat sebagai agen pereduksi, nanopartikel perak yang disintesis menggunakan asam salisilat memiliki ukuran yang lebih besar. Ukuran nanopartikel perak yang dihasilkan ketika menggunakan $\mathrm{m}^{-}$ hidroksibenzoat sebagai agen pereduksi adalah $19 \pm 9 \mathrm{~nm}^{[9]}$, sedangkan nanopartikel perak yang dihasilkan saat menggunakan $p$-hidroksibenzoat sebagai agen pereduksi memiliki ukuran sebesar $26 \pm 11 \mathrm{~nm}^{[8]}$. Rasio mol antara larutan perak nitrat dengan agen pereduksi dan agen penudung dapat mempengaruhi ukuran partikel. Rasio mol antara perak nitrat dengan asam salisilat lebih besar jika dibandingkan dengan rasio mol perak nitrat dengan $m$-hidroksibenzoat maupun $p$-hidroksibenzoat. Peningkatan konsentrasi agen pereduksi dan agen penudung dapat mempengaruhi peran agen penudung untuk menghasilkan partikel yang lebih besar karena susunan molekul agen penudung dalam jumlah yang lebih besar menyediakan ruang yang lebih besar untuk pertumbuhan nanopartikel perak ${ }^{[9]}$. 


\subsection{Stabilitas Nanopartikel Perak Tertudung Asam Salisilat}

Stabilitas nanopartikel perak tertudung asam salisilat hasil sintesis diukur selama masa penyimpanan. Pengukuran stabilitas nanopartikel perak tertudung asam salisilat dilakukan dalam beberapa waktu yaitu 1 hari hingga 16 minggu setelah proses sintesis. Stabilitas nanopartikel perak diamati melalui tiga parameter, yaitu posisi panjang gelombang maksimum ( $\lambda$ maks), intensitas puncak serapan, dan lebar puncak atau FWHM (full width half maximum) ${ }^{[10]}$.

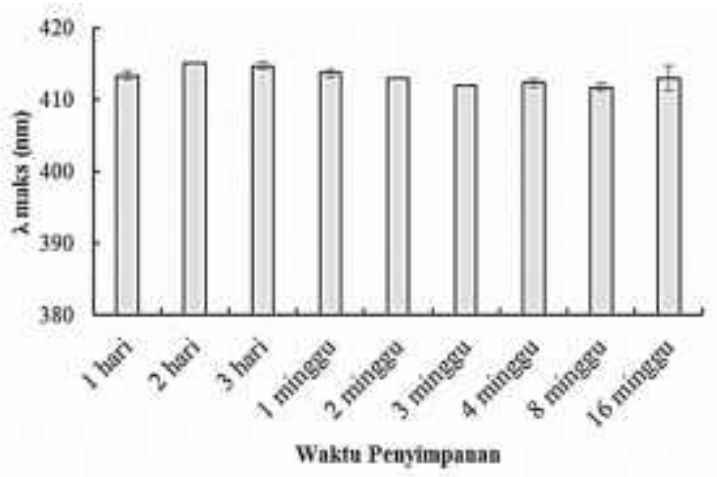

A

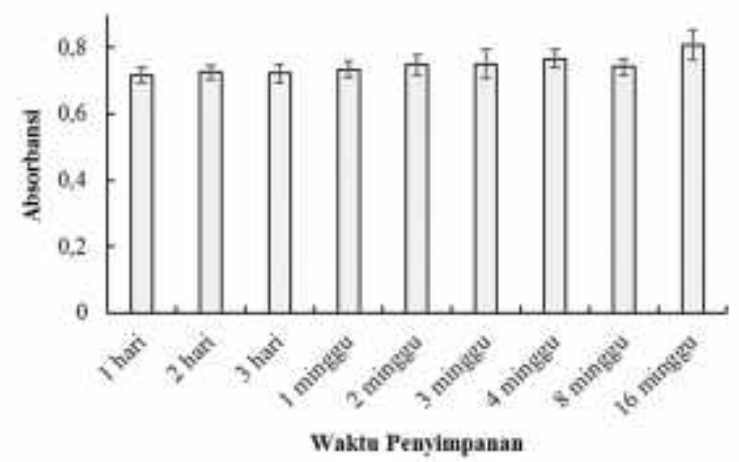

B

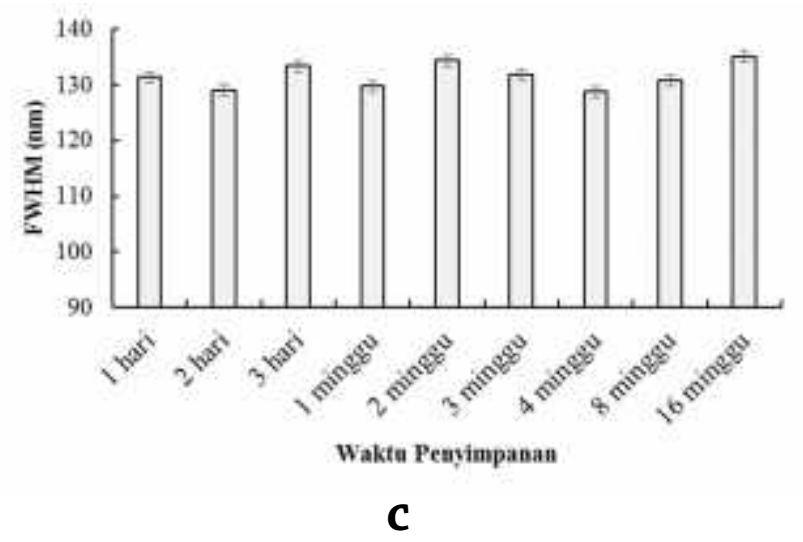

Gambar 5. Perubahan parameter stabilitas nanopartikel perak tertudung asam salisilat selama masa penyimpanan (a), panjang gelombang maksimum (b), absorbansi (c), FWHM

Pada Gambar 5a terlihat posisi panjang gelombang maksimum selama masa penyimpanan. Posisi panjang gelombang berfluktuasi selama penyimpanan dengan kisaran perubahan sebesar 1-4 nm. Posisi panjang gelombang maksimum berkisar dari 411 sampai $415 \mathrm{~nm}$. Adanya pergeseran posisi panjang gelombang maksimum menunjukkan terjadinya perubahan ukuran partikel. Meskipun terjadi sedikit pergeseran posisi panjang gelombang, namun dapat dikatakan posisi panjang gelombang maksimum relatif konstan. Selain panjang gelombang maksimum, diamati pula intensitas puncak serapan pada setiap waktu pengukuran sebagaimana terlihat pada Gambar 5b. Terjadi peningkatan absorbansi sebesar 13\% dari pengukuran pada waktu 1 hari setelah sintesis hingga 16 minggu penyimpanan. Hal ini menunjukkan bahwa selama masa penyimpanan masih terjadi proses reduksi $\mathrm{Ag}^{+}$menjadi $\mathrm{Ag}^{0}$ untuk membentuk nanopartikel perak. Selain posisi panjang gelombang maksimum dan intensitas puncak serapan, parameter yang diamati selanjutnya yaitu perubahan lebar puncak spektra resonansi plasmon permukaan nanopartikel perak sebagaimana terlihat pada Gambar 5c. Terjadi fluktuasi perubahan lebar puncak yang berkisar dari 128 sampai $131 \mathrm{~nm}$. Hal tersebut mengindikasikan distribusi ukuran 
partikel relatif tidak mengalami perubahan. Adanya perubahan distribusi ukuran partikel disebabkan oleh agregasi atau interaksi antar nanopartikel yang membuat ukuran partikel menjadi lebih besar sehingga terjadi pelebaran puncak ${ }^{[10]}$.

Pada Gambar 6 dapat diamati spektra nanopartikel perak setelah penyimpanan selama 16 minggu. Meskipun terdapat sedikit perubahan pada posisi panjang gelombang maksimum, intensitas puncak serapan, dan lebar puncak sebagaimana terlihat pada Gambar 5, namun dapat dikatakan bahwa nanopartikel perak tertudung asam salisilat memiliki tingkat kestabilan yang tinggi. Keberadaan nanopartikel perak dapat ditunjukkan oleh masih terlihatnya puncak serapan pada panjang gelombang $420 \mathrm{~nm}$ setelah 16 minggu penyimpanan sebagaimana terlihat pada Gambar 6. Penelitian yang telah dilakukan sebelumnya menunjukkan bahwa nanopartikel perak yang disintesis dengan penambahan agen penudung Twen-20 dapat bertahan selama 2 minggu $^{[2]}$. Nanopartikel perak yang disintesis dengan penambahan agen penudung polivinil alkohol juga dapat bertahan selama 2 minggu $^{[6]}$. Hasil eksperimen yang diperoleh menunjukkan bahwa asam salisilat dapat berfungsi sebagai agen penudung dalam menghasilkan nanopartikel perak yang lebih stabil selain sebagai agen pereduksi.

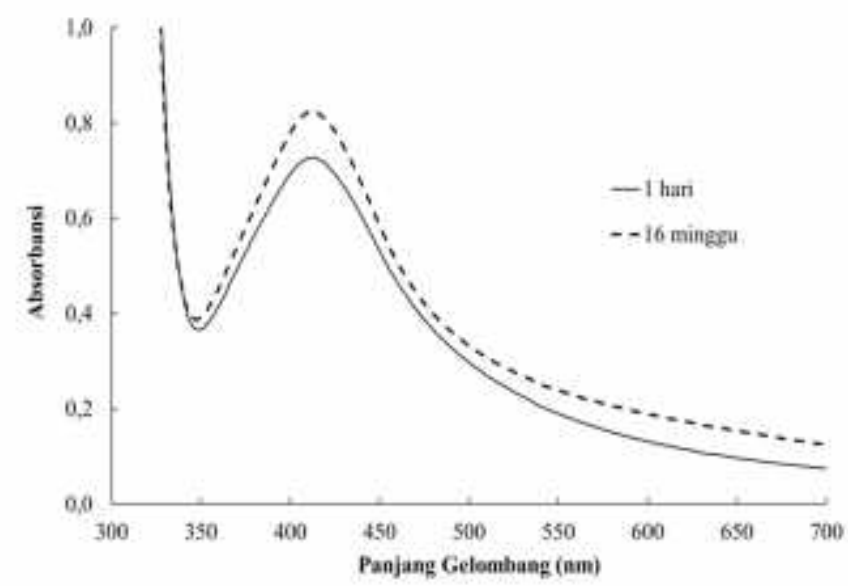

Gambar 6. Spektra resonansi plasmon permukaan nanopartikel perak setelah 16 minggu masa penyimpanan

\section{Kesimpulan}

Nanopartikel perak dapat disintesis melalui reduksi ion perak dengan asam salisilat. Nanopartikel yang disintesis menggunakan perak nitrat dan asam salisilat dengan perbandingan mol 1:40 menghasilkan partikel dengan ukuran rata-rata $66 \pm 28 \mathrm{~nm}$ dan menunjukkan kestabilan yang tinggi selama 16 minggu penyimpanan. Hal ini menunjukkan bahwa asam salisilat selain berfungsi sebagai senyawa pereduksi sekaligus berfungsi sebagai agen penudung.

\section{Daftar Pustaka}

[1] Singh, D., Rathod, V., Ninganagouda, S., Hiremath, J., Singh, A.K., Mathew, J., Optimization and Characterization of Silver Nanoparticle by Endophytic Fungi Penicillium sp. Isolated from Curcuma longa (Turmeric) and Application Studies Against MDR E. coli and S. aureus. Bioinorganic Chemistry and Applications. 2014; 2014: 1-8.

[2] Sulistiawaty, L., Sugiarti, S., Darmawan, N., Detection of $\mathrm{Hg}^{+2}$ Metal Ions Using Silver Nanoparticles Stabilized by Gelatin and Tween-20. Indonesian Journal of Chemistry. 2015; 15(1): 1-8. 
[3] Wahyudi, T., Sugiana, D., Helmy, Q., Sintesis Nanopartikel Perak dan Uji Aktivitasnya terhadap Bakteri E. coli dan S. aureus. Arena Tekstil. 2011; 26(1): 1-60.

[4] Saputra, A.H., Haryono, A., Laksmono, J.A., Anshari, M.H., Preparasi Koloid Nanosilver dengan Berbagai Jenis Reduktor sebagai Bahan Anti Bakteri. Jurnal Sains Materi Indonesia. 2011; 12(3): 202-208.

[5] Junaidi, A.B., Wahyudi, A., Umaningrum, D., Sintesis AgNPs Secara Reduksi Kimia Menggunakan Capping Agent Kitosan dan Pereduksi Glukosa. Sains dan Terapan Kimia. 2015; 9(2): 70-80.

[6] Apriandanu, D.O.B., Wahyuni, S., Hadisaputro, S., Harjono., Sintesis Nanopartikel Perak Menggunakan Metode Poliol dengan Agen Stabilisator Polivinilalkohol (PVA). Jurnal MIPA. 2013; 36 (2): 157-168.

[7] Annadhasan, M., Muthukumarasamyvel, T., Babu Sankar, V.R., Rajendiran, N., Green Synthesized Silver and Gold Nanoparticles for Colorimetric Detection of $\mathrm{Hg}^{2+}, \mathrm{Pb}^{2+}$ and $\mathrm{Mn}^{2+}$ in Aqueous Medium. ACS Sustainable Chemistry Engineering. 2014; 2(4): 887-896.

[8] Gusrizal, G., Santosa, S.J., Kunarti, E.S., Rusdiarso, B., Dual Function of $p$-Hydroxybenzoic Acid as Reducing and Capping Agent in Rapid and Simple Formation of Stable Silver Nanoparticles. International Journal of ChemTech Research. 2016; 9(8): 472- 482.

[9] Gusrizal, G., Santosa, S.J., Kunarti, E.S., Rusdiarso, B., Synthesis of Silver Nanoparticles by Reduction of Silver Ion with m-Hydroxybenzoic Acid. Asian Journal of Chemistry. 2017; 29(7): 1417-1422.

[10] Gusrizal, G., Santosa, S.J., Kunarti, E.S., Rusdiarso, B., Two Highly Stable Silver Nanoparticles: Surface Plasmon Resonance Spectra Study of Silver Nanoparticles Capped with mHydroxybenzoic Acid and p-Hydroxybenzoic Acid. Molekul. 2018; 13(1): 30-37.

[11] Baghizadeh, A., Ranjbar, S., Gupta, V.K., Asif, M., Pourseyedi, S., Karimi, M.J., Mohammadinejad R., Green Synthesis of Silver Nanoparticles Using Seed Extract of Calendula officinalis in Liquid Phase. Journal of Molecular Liquids. 2015; 207: 159-163. 